\section{A study on the advantages, difficulties, functions, and strategies of creative education in elementary schools of Taiwan}

\author{
Lin, Pi-Fang $\bowtie$ \\ NTNU Extension School of Continuing Education, Taiwan, ROC (bella910@ms95.url.com.tw)
}

Received: 30 September 2012

Available Online: 8 April 2013 DOI: $10.5861 /$ ijrse.2013.429
Revised: 20 March 2013

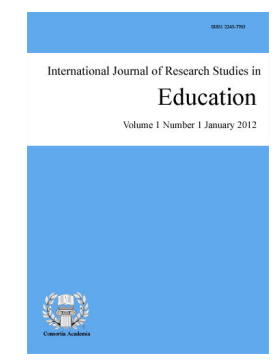

ISSN: $2243-7703$ Online ISSN: 2243-7711

OPEN ACCESS

\title{
Abstract
}

21 st century is a global knowledge based economy, the key in order to fully embrace this changing world is to develop one's innovation and creative ability. Currently, Taiwan's Creative Education policies had already been in place for quite some time, therefore, the main purpose of the study is to investigate the different factors like advantages, difficulties, functions and strategies that affect the development of Creative Education in the elementary students of Taiwan. The study uses a survey questionnaire method in collecting data. The participants are members of the elementary school community, which includes principals, supervisors, class advisers, subject teachers, and non-teaching staffs. The number of valid questionnaires is 213 teachers. Advantages includes: openness of school to change, support of school administrators, hardware and software availability, resource availability, and support of parents. Difficulties includes: teachers' pressure in keeping up with the advancement of lessons, not enough time to go into creative education, lack of facilities and funding in promoting creative education, and parent's old concept of education. Functions includes: enhance the students' imaginative and creative thinking, motivate students' interest in learning, and improve teachers' creative education skills. Strategies includes: campus wide competition, encourage cooperation in teachers while joining research discussions, sharing experiences and job trainings to further improve their professional skills.

Keywords: creativity; elementary schools; survey; quantitative study; Taiwan 


\section{A study on the advantages, difficulties, functions, and strategies of creative education in elementary schools of Taiwan}

\section{Introduction}

The development of Creative skills is truly important. Creativity master Mihaly Csikszentmihalyi once said

that the human genes are $98 \%$ similar with primate genes and yet we are much different in many areas. Human beings after undergoing learning creates various forms of outcomes like language, value concept, artistic expression, and science and technology. Human beings need to be affirmed and rewarded. Therefore, without "creativity" humans and primates would just be the same.

The $21^{\text {st }}$ century is a global knowledge based economy, the key in order to fully embrace this changing world is to develop one's innovation and creative ability. Taiwan realizing this global trend, therefore in order to be in pace with the world, in early 2002, the Advisory Office of the Ministry of Education announced the White Paper on Creative Education, with the goal of creating a Republic of Creativity in Taiwan. This plan will develop the people's creative skills, in order to uplift its competitiveness in the global market. With this vision, the "Project on the Enhancement of Creative Education" was established. The major objective of this project is to cultivate creative students with the use of various educational policy implementations.

Creative education now is not only concentrated on academic works, but rather will play an even more important role in the future. Currently, the implementation of the "Creative Education Policy" has been in place for some time. A number of academic researchers have focused on the implementation status and situation of creative education. But most of the researches are focused on understanding only both the advances and disadvantages of creative education. Some other researches placed importance on the study of the causes and reasons on creative education implementation difficulties, without doing an experimental study (e.g. Zheng 2005). With respect to the advantages, difficulties, functions and strategies on implementing Creative Education on the elementary students, systematic empirical research are rarely done. Therefore, in light of these current situations and after going over through various related literatures, the researcher decided to undergo this study. This study utilizes a questionnaire as research tool to gather the needed information. This study aims to:

$>$ Understand the advantages of implementing Creative Education on elementary students.

$>\quad$ Understand the difficulties of implementing Creative Education on elementary students.

$>\quad$ Analyze the different functions of Creative Education on elementary students.

$>$ Introduced strategies that would help promote Creative Education on elementary students.

$>\quad$ Understand the effects of teacher's characteristics on the implementation of Creative Education on elementary students.

\section{Review on related literature}

\subsection{Origin and development of creative education in Taiwan}

In 1946 the government of Taiwan started to place great emphasize on creative policy. The national government announces the National Constitution Article 166, which states the provision that the country should reward scientific invention and creation. In 1983, Taipei city's Bureau of Education hosted the Taipei Creative 
The role of different stakeholders in Ethiopia in the improvement of educational quality

Thinking Education Seminar, with Secretary Mao (Chief, Bureau of Education - Taipei City) giving full support in promoting Creative Education. This seminar is remembered as one of the milestone of Creative Education history in Taiwan, although during that time Creative Education has not yet deeply been promoted in the whole country.

In 1984, Taipei city's Bureau of Education created the Creative Education Assistance Program. This program provides workshops and seminars throughout the country, hence successfully expanding the concept and idea of Creative Education. In 1996 the government under the Executive Educational Reform announced the Multi-facet, colorful and vivacious Creativity Program as the direction of modern education. This also marks the start of the Creative Education era in Taiwan.

In 1998, the Ministry of Education proposed the Towards a Learning Society White Paper, to promote life-long education. This white paper proposed 14 reform policies to help promote and develop "Creativity". In the same year, the Ministry of Science and Technology announced the Science and Technology Innovation Research Program, supporting numerous researches towards promotion of innovation. Projects include scientific research and study, scholarship grants for students and teachers, environmental education and many others.

In 2000, the government announced the National Education 9 years Integrated Curriculum Program with the aim in developing the students 10 Basic Skills. Some of the basic skills include appreciation, performance and creativity and ability to make critical thinking and solve problems. In the same year, the Ministry of Education launches the Strengthen Innovation and Learning Ability Strategy, envisioning that in the year 2010, Creative Education be implemented in all areas of education. At the same time, establishing an atmosphere well suited for creative learning, thus strengthening the creative capability of not only the students but the teachers as well.

Currently, local education offices are already in the midst of implementing Creative Education. Some important key factors in the development of Creative Education are the following: 1) Encourage inter-county creative groups; 2) Established assessment indicators, through gathering of quantitative data, enabling better understanding of the student's learning situation; 3) Encourage all the county and municipal governments to establish a Creative Education promotion committee, to help organize and promote Creative Education Policies; 4) Hold local Creative Education Fair, in order a place for inter-county exchanges and help promote creative achievements.

In abroad, Creative Education is spreading like wildfire. Wu et al. (2002) did a study focusing on 14 countries and regions. His studied was centered on the various creative policies, the systems of leaders, and the Creative Education programs and education goals. Some results are as such: Singapore fosters creativity by way of innovation in daily living; in Japan a famous television program gives opportunity for the people to join and show their creative talents; in South Korea industry innovation is being develop actively; while in Australia a culture of creative ideas is being promoted; and in the United States, American university and research institutions are actively involved in creative research, education and its promotion. In England, Creative Education is combined with cultural education and in France, a place rich with creative living and living innovation. These are all important points where Taiwan can follow and study.

\subsection{Creative education researches}

Einstein once said that imagination is more important than knowledge, because knowledge is limited, while imagination can roam the world. In order to meet the arrival of the age of creative economy, the government sustains some focal point classifying them as national development in recent years. The Ministry of Education's Creative Education is one of the most important projects that the policy actively promotes. Not only in the matter of academic or of the practical world, much study is based on the investigation of the present education situation like obstruction, helping hand, function and push tactics that influence Creative Education. 
Chan (2002) Regard students' creativity as the core in the students learning system, which is consist of the following relevant teacher factors, campus environment, and school's administration and outside community. Some findings that arise from the study are for the teachers who have the inherent motive to teaching; can promote knowledge circulation, cooperate in sharing, and pursue professional growth. Teacher's help train and set goals for students. The teachers have a creative and lively teaching style, thus brings out the creativity of the students, develops their motivation to learn, train them on how to pinpoint the problems, encourage a wide perspective view, encourage student is it try, learn to forgive failure student, and many others. In the school environment, the study found out that if the school culture and its physical facilities helped develops a students' creativity. In the administrative part of the school, the administrative personnel should lead and influence teachers and students in developing creativity.

In addition Chan (2003), in a study on the actual conditions of Creative Education Policies in elementary school of Taiwan. Found out from students, teachers curriculum teaching, school management, educational administration and parents, have 12 favorable conditions as to 18 unfavorable conditions in relation to Creative Education. Chou (2003) also states that the fostering creativity in the school includes inviting lecturers from outside the school, build an atmosphere of creativity, change the environment of the classroom, encourage students to give suggestion and question, joining systematic activities, holding constructive competition, increase the number of creativity related books and computer software, answer demand of new century by strengthening academic course content, use of peer tutoring, adopt a multi-faceted assessment strategy, strengthen reading and writing ability, and the use of active teaching strategy to further accelerate learning.

Teng (2005) states that while implementing creativity education, some problem that arises are pressure cause by national examinations, insufficient information dissemination among parents and teachers, and the lack of basic facilities in promoting Creative Education. The study also proposed 5 methods to answer the aforementioned problems, namely: Education system reform, lighten school pressure, strengthen information dissemination, transmit the idea of creativity amongst students, school should offer an environment that not only innovate but support Creative Education, hold creativity training for teachers to increase and promote the teachers' knowledge, and cooperation with the community enterprise in order to learn outside experiences.

$\mathrm{Wu}$ (2006) states that the overall goal of Creative Education includes: Creative opportunity, creative teaching, creative administration, creative facilities and culture. He also proposed some strategies, which includes: 1) Engaged in the background analysis of the school, to be able to handle the development of the school better; 2) Creates an educational creativity goal, to help guide the school organization; 3) The school principal should have the courage to overcome obstacle, to be able to lead and face challenges; 4) Organize a creative administrative group to help promote creative administration; 5) Conduct creative training activities, in order to uplift creative knowledge; 6) Seek creative suggestions from members, in order to transform the schools environment; 7) Encourage creative teaching, enhance student's enjoyment of studying; 8) Build the school's creative atmosphere and establish a creative culture; and 9) Utilize community resources in helping the overall school.

\subsection{Creative education assessment index}

In psychometric test the term index is used to express in a single expression the results gathered from multiple variables. The magnitude of the expression is represented by the power of interaction amongst of the variables (Zhang, 1995). Creative Education index is based upon the construct of something measurable, a Creative Education assessment criterion. This test can serve as a clear tool for benchmarking Creative Education in schools. Studies in the past have been focused on school's creative index. Hong et al. (2002) focuses on the study of the elementary teacher's teaching styles. They found out that Creative Education index includes the following: Knowledge capacity, emotion and expression, critical thinking, associative thinking, problem finding and solving, information strength, and creative expression. While Chen (2002) propose the designing of an index which are included in a training program in Creativity, namely: LOVE - as the core, ASK - as the starting point. 
The role of different stakeholders in Ethiopia in the improvement of educational quality

ASK includes the attitude, skill and technique, and knowledge. Zheng and Wang (2002) did a comparison between ordinary teachers and excellent science teachers who frequently joined contests. The study points out 17 important indicators which influence creativity. Some factors are school, teacher's specialization, parents, school administration and school environment, and many others. While, Pan (2004) proposed that school creativity indicators are namely: Teacher personal indicator, multi-culture indicator, organization atmosphere indicator, school academic environmental indicator, arts and literature indicator, achievement and research indicator.

At present, there are a lot of studies about creativity and creative education, but so far there is not one study that can clearly assess creative education. As a starting point, this study utilizes 32 assessment indicators to evaluate creative education policies.

\section{Research methodology}

\subsection{Data}

The respondents of this study are the Taiwan elementary school teachers and staffs (including School principal, supervisors and department heads, class advisers, subject teachers, and together with the schools' administrative personnel). In order to have a valid sample, the researcher utilizes a sample coming from the whole population of elementary schools in the 24 different counties all over Taiwan. From the 24 counties, the researcher selected 11 counties, with a total of 27 elementary schools and 213 teachers as respondents to the survey questionnaire. Male respondents consists of 62 persons almost $29.2 \%$ of the total respondents, while female respondents total to 150 , which is $70.8 \%$ of the total respondents. About $43.5 \%$ of the respondents in on the age bracket of 30 to 40 years old, while about $30.0 \%$ of the respondents are on the age bracket of 40 to 50 years old. The average age is about 35.8 years old. In work tenure, the majority of the teachers with $31.5 \%$ of the respondents had work tenure ranging from 0 to 5 years, while the average work tenure is about 11.1 years. With respect to educational attainment, almost $70.3 \%$ of the respondents are college graduates, with $69.9 \%$ of the respondents coming from a teacher's normal college. About $24.2 \%$ of the respondents had taken up education units. About $58.8 \%$ of the respondents are class advisers and about $29.4 \%$ of the respondents are department heads and supervisors.

\subsection{Research tool}

The researcher designed her own research tool, which is the Elementary School's Creative Education Questionnaire. Initially, the researcher solicits voluntary comments from 57 elementary school teachers. These comments are mostly directed on what are the advantages in promoting Creative Education, problems in implementation, functions of Creative Education and helpful strategies in implementing Creative Education, etc. After careful analysis and categorizing of the comments, an initial sample of the questionnaire was form. In order to make the questionnaire more valid, the researcher let 5 elementary school teachers and 3 professional educators go over the questionnaire again. After the taking note of the comments; revisions are made into the final version of the Elementary School's Creative Education Questionnaire.

The research tool seeks to find information of the respondents with respect to the following: gender, age, tenure of work, highest educational attainment, educational background, rank, creativity award-winning experiences, and experiences in joining into creativity competition with the students. With respect to the schools' profile, school size and location was also asked. With regards to the implementation of Creative Education a total of 17 questions were asked. For problems in the implementation of Creative Education a total of 13 questions were asked. With respect to the function of Creative Education a total of 16 questions were asked. Lastly, in relation to the strategies involved in the implementation of Creative Education a total of 32 questions were asked. The respondents are asked to place a check on the boxes besides every number, with the rankings 1 (not very important) to 6 (very important). 


\section{Analysis of results}

\subsection{Advantages of schools implementing Creative Education}

The school's teachers and staff view of the Advantages of schools implementing Creative Education are as follows: "teacher's teaching independence generally improved" with $63.5 \%$, "the teacher would like to share teaching experience" with $62.1 \%$, "teacher with specialize accomplishment and expertise" with $61.1 \%$, and "different teacher's teaching style" with $60.2 \%$. These are the current advantages of schools implementing Creative Education. From the results, the researcher found out that almost over $60 \%$ of the teachers believed that advantages of implementing Creative Education lies with the faculty itself. This finding is also very similar to Chan (2002) research results.

\subsection{Difficulties of schools implementing Creative Education}

Schools' teachers and staffs all viewed that there are indeed difficulties in the implementation of Creative Education. The statistical summary of the surveyed results are the following: "teacher's pressure for advancement (promotion)" with 78.1\%, "teachers lack the time in designing creative lessons" with 58.6\%, and "students' examination pressures" with 51.0\%. From the results, the researcher points out that the main problems that the teachers encounter while implementing Creative Education are mostly lack of time and advancement pressures, coupled with the students' examinations pressures. These results are very much similar to Teng (2005) findings as well.

\subsection{Functions of schools implementing Creative Education}

Schools' teachers and staffs viewed that the functions of school implementing Creative Education are the following: "enhance the students' ability in expressing themselves" with $67.0 \%$, "motivates students' on learning" with $63.1 \%$, "enhance students' imaginative and creative skills" with $58.3 \%$, "encourage students' cooperative learning" with $56.3 \%$, and "enhances the students' vision and curiosity" with $51.5 \%$. From the results, the researcher points out that the main function of Creative Education is to be able to motivate student in the areas of learning and at the same time develops their creative skills.

\subsection{Strategies of schools implementing Creative Education}

This most important goal of this study is to find the best strategies in implementing Creative Education in elementary schools of Taiwan. After careful analysis of the survey questionnaire, the researcher found out that the following strategies are the most helpful in the implementation of Creative Education: "encourage teachers to join professional trainings and seminar" with 59.4\%. This result is much similar with various studies (Chou, 2003; Teng, 2005; Wu, 2006). "Develops the schools' uniqueness" with 58.5\%, "utilizing state funds in order to substantiate school equipments for Creative Education usage" with 57.5\%, "encourage teachers to join discussions and exchange forums" with $56.5 \%$ and "organizing school wide activities to display students' works for public viewing" with $50.2 \%$.

Based on the respondents regarding the importance of "Strategies of schools implementing Creative Education" within the 32 strategies, only "using experts in grading the performance of teachers, to select the most creative teacher" garner a score of between "not so important" (3 points) and "a little important" (4 points). While for the rest of strategies the score are between "a little important" (4 points) and "important" (5 points). Within them "utilizing state funds in order to substantiate school equipments for Creative Education usage" scored 5.23 points, "schools need to give financial and manpower support to teachers who are implementing Creative Education" scored 5.19 points, and "utilizing various rewards and incentives, in order to promote the use of Creative Education among teachers" scored 5.09 points. 
The role of different stakeholders in Ethiopia in the improvement of educational quality

With regards to "strategies the school used in implementing Creative Education" and "the perceived importance of Creative Education policy of the teachers". Only the "utilizing state funds in order to substantiate school equipments for Creative Education usage" showed consistency in the results. But only "schools need to give financial and manpower support to teachers who implementing Creative Education" and "are utilizing various rewards and incentives, in order to promote the use of Creative Education among teachers" strategies, had won the confidence of the respondents and were therefore considered important strategies. Their ranks are 12 and 16 respectively.

\subsection{Significant difference were found between the different background of teachers and the implementing policy \\ of Creative Education}

In order to fully understand if there is a significant difference between the different teacher's background factors and the different strategies in the implementation of Creative Education, the researcher utilizes the t-test and ANOVA to test the differences between gender, province of origin, educational background, nature of job, and school size with the implementation of Creative Education strategies.

With results as such: There is no significant difference between gender and the implementation strategies of Creative Education in schools $(\mathrm{t}=0.196, \mathrm{p}>0.05)$. There is no significant difference between the different province of origin and the implementation strategies of Creative Education in schools $(t=-0.156, p>0.05)$. There is no significant difference between the various teachers' educational backgrounds (graduate from an education normal college, taken educational units, other education related courses) and the implementation strategies of Creative Education in schools $(\mathrm{F}=2.56, \mathrm{p}>0.05)$. However, there is significant difference between the different nature of job (department head \& supervisor, class adviser, subject teacher, administrative staffs) and the implementation strategies of Creative Education in schools $(\mathrm{F}=2.775, \mathrm{p}<0.05)$. After continued analysis, the researcher found out that the department head and supervisor had a larger effect than the class adviser. For the school size factor, there is no significant difference between the school size (with 12 and above classes, between 13 to 24 numbers of classes, 25 and above number of classes) and the implementation strategies of Creative Education in schools $(\mathrm{F}=0.121, \mathrm{p}>0.05)$.

With the following results, the researcher found out that only the different nature of job (different position in school) had have a considerable effect on the implementation of strategies for Creative Education in elementary schools. While for the other factors like gender, province of origin, educational background, and school size, would not have a significant effect on the strategies.

\section{Conclusions and recommendations}

\subsection{Conclusions}

This main purpose of this study is to know more about the advantages, difficulties, functions and strategies that are involve in promoting Creative Education in the elementary schools of Taiwan. The conclusions are as such:

(1) The main advantage of schools in the implementation of Creative Education is the teacher factor

When schools promote Creative Education, there must be suitable conditions present to be able to have the most positive effect. According to the study, when schools promote Creative Education, the most favorable conditions is that "the teacher's teaching independence generally improve", followed by "the sharing of teaching experiences between teachers". Some other benefits are "teachers' improvement in their professional skills" and "teacher's unique individual teaching styles". The above mentioned advantages are prevalent in more than $60 \%$ of the respondents. 
(2) The main difficulties in the implementation of Creative Education are teacher's time pressure and student's examination pressures

Every education policy has to meet some implementation difficulties. According to this study, the main difficulty in the implementation of Creative Education is the "teacher's pressure for advancement (promotion)" with $78.1 \%$ of the respondents having this kind of problem. The second barriers are "teachers' lack the time in designing creative lessons" and "students' examination pressures". From the findings, the researcher found out that the sources of these difficulties are all psychological related pressures.

(3) The main function of implementing Creative Education is to improve both the students' motivation and ability in learning

In every undertaking there must be a function (reason) and these functions hopefully should have a big impact. According to this study, the main function of Creative Education implementation are "enhance the students' ability in expressing themselves", followed by "motivates students' on learning" and "enhance students' imaginative and creative skills" , "encourage students' cooperative learning", and "enhances the students' vision and curiosity". Almost more than 50\% of the respondents agreed on the above mentioned functions. Creative Education main function is to improve the students' creativity. Therefore, with these results, the researcher believes that investing on Creative Education is a worthwhile venture.

(4) The most effective strategies in implementing Creative Education are encouraging teachers to join professional trainings and activities

In the implementation of Creative Education, in order to become successful schools utilized various strategies. According to this study, "encourage teachers to join professional trainings and seminar" is the best strategy, followed by "Develops the schools' uniqueness", "utilizing state funds in order to substantiate school equipments for Creative Education usage", "encourage teachers to join discussions and exchange forums", and “organizing school wide activities to display students' works for public viewing”.

(5) Difference in gender, province of origin, educational background, and school size those not have a significant effects on the implementation strategy of Creative Education

According to this study, difference in gender, province of origin, educational background, and school size those not have a significant effects on the implementation strategy of Creative Education. This indicates that Creative Education is a meaningful program and has consistencies in its results.

\subsection{Recommendations}

(1) Encourage schools to promote Creative Education in order to uplift the student's creativity

The study shows that almost over $50 \%$ of the respondents believed that improving the students' creativity is the major function of Creative Education. Currently, there are still some a number of schools in the 24 counties of Taiwan who are still not implementing Creative Education. Education department should encourage the implementation of Creative Education, so that every school could "develop the creativity of their students" and at the same time have a "creative educational management". Rewards can also be given to outstanding schools as a sort of encouragement to schools as well.

(2) Conduct various free seminars and trainings, in order to help uplift the teachers' professional skills

The study shows that most respondents believed that "encourage teachers to join professional trainings and seminar" is the best implementation strategy, while the main advantage is "teachers' improvement in their professional skills". Therefore, increasing the number of trainings and seminar should continue to improve the creativity of teachers, hence improve their teaching skills as well. 
The role of different stakeholders in Ethiopia in the improvement of educational quality

(3) Allocate funding to help schools promote and develop Creative Education

The study shows that "utilizing state funds in order to substantiate school equipments for Creative Education usage" is one of the feasible strategy that a school could adopt. Therefore, a school should apply yearly for such financial assistance, in order to substantiate the equipment and facilities, hence aid in Creative Education implementation.

(4) Reducing the basic administrative works of teacher

This study found out that one of the important difficulties the teachers encounter during the implementation of Creative Education is the "teacher's pressure with the teaching process" and "the lack of time in preparing creative lessons". One of the main reasons why the teachers don't have ample time is because of the various administrative tasks that are assigned to them. Therefore, in order to give the teachers more time in designing and preparing their lessons, the researcher suggest that the basic administrative tasks of teachers be lessen, so as to increase the performance of Creative Education.

(5) Promote and develop school's uniqueness

This study found out that one of the most successful strategies in the implementation of Creative Education is to "develop the school's uniqueness". Therefore, school administrators should direct the whole school into achieving this goal.

(6) Instill a wholesome school atmosphere and culture, thus promote camaraderie and cooperation among teachers and staffs

According to the findings, "encourage teachers to participate in classroom teaching and discussion, and sharing of experiences" is one of the most effective Creative Education implementing strategies. If both the teachers and students could cooperative in and between schools, sharing of information with regards to teaching methods and curriculum design would be beneficiary to all the parties. Therefore, schools should promote a harmonious atmosphere, in order to promote Creative Education.

(7) Organize various school activities to promote creative motivation among student

This study found out that the annual school activity, such as school gatherings could easily be used as a venue for showing and displaying student's creative works for public viewing, hence, giving publicity to Creative Education achievements. Student's work should be shown, viewed and admired by teachers and students of the whole school during public occasion. This would give encouragement to the student and help motivate them.

(8) Suggestion for future researches

This study provides an initial Creative Education assessment index, with only 213 elementary school teachers and staffs as respondents. Future study could further verify the validity of the former's result with the use of a larger sample. The results will be give insights to schools in implementing Creative Education.

\section{References:}

Chan, C. Y. (2002). Factors that affect creativity. Student Counseling, 79, 32-47.

Chan, C. Y. (2003). Conditions and policies in promoting Taiwan creativity education in the primary and secondary schools [In Chinese]. Journal of Education and Psychology, 106, 20-36.

Chang, C. H. (1995). Chang psychology dictionary [In Chinese]. Taipei City: Tunghua Bookstore.

Chen, L. A. (2002). The study on the effectiveness of creative teaching strategy in the elementary and junior high school [In Chinese]. International symposium on creativity curriculum development (pp. 185-214). Taipei: National Taiwan Normal University Press. 
Lin, P. F.

Chen, Y. H. (2006). 2006 Annual workshop on creative education promotion program. Taipei: Ministry of Education.

Cheng, Y. Y., \& Wang, W. C. (2002). Factors affecting science competition winner teachers' creative behavior [In Chinese]. Research in Applied Psychology, 15, 163-189.

Chou, F. J. (2003). Creative education promotion strategies [In Chinese]. Teacher Talks, 172, 27-30.

Hong, J. C., Lin, Y. L., \& Lin, C. L. (2002). A study on the effectiveness of creative teaching strategies in elementary and junior high school [In Chinese]. International symposium on creativity curriculum development (pp. 125-145). Taipei: National Taiwan Normal University Press.

Pan, Y. F. (2004). School creativity research indicators [In Chinese]. Creative Thinking Education, 14, 19-25.

Teng, M. C. (2005). Implementing creativity education predicament with a suitable response [In Chinese]. Teacher Talks, 186, 43-45.

Wu, C. J., Lin, W. W., Lin, S. Y., Chen, C. S., Tseng, C. M., Wang, H. I., \& Hsu, Y. C. (2002). The international trend in creativity education development [In Chinese]. Gifted Education Research, 2(1), 1-26.

Wu, C. S. (2006). Theory and practice of creative school development [In Chinese]. Teachers' Journal, 142, 9-15. 